\title{
Numerical model of the aortic root and valve: Optimization of graft size and sinotubular junction to annulus ratio
}

\author{
Gil Marom, MSc, ${ }^{\text {a }}$ Rotem Halevi, MSc, ${ }^{\mathrm{a}}$ Rami Haj-Ali, PhD, ${ }^{\mathrm{a}}$ Moshe Rosenfeld, DSc, ${ }^{\mathrm{a}}$ \\ Hans-Joachim Schäfers, MD, ${ }^{b}$ and Ehud Raanani, MD $^{c}$
}

\begin{abstract}
Objective: The aim of this study was to determine the influence of aortic annulus (AA) diameter and the ratio of the sinotubular junction (STJ) diameter to the AA diameter on aortic valve hemodynamics and tissue mechanics and to suggest optimal values.
\end{abstract}

\begin{abstract}
Methods: Sixteen cases of aortic roots with AA diameters between 22 and $28 \mathrm{~mm}$ and an STJ/AA diameter ratio between 0.8 and 1.4 were numerically modeled. Average coaptation height and mechanical stresses were calculated from 3-dimensional finite element analysis of the aortic valve and root. Five additional fluid structure interaction (FSI) models with an AA diameter of $24 \mathrm{~mm}$ and an STJ/AA ratio between 0.6 and 1.4 were also constructed. The material properties of the tissues were from porcine valves and boundary conditions were physiologic and normal blood pressures.
\end{abstract}

Results: In most cases, average coaptation height decreased with an increase in the STJ/AA ratio. Those cases with AA diameters between 24 and $26 \mathrm{~mm}$ and an STJ/AA ratio between 0.8 and 1.0 had a relatively large average coaptation height $(>3 \mathrm{~mm})$ and similar stress distribution during diastole. The flow shear stress values on the cusps at peak systole increased at the same time as the STJ/AA ratio decreased, similar to the opening area.

Conclusions: Relatively large coaptation, low stress in the tissues during diastole, and low flow shear stress during systole is the best combination for cases of AA diameter between 24 and $26 \mathrm{~mm}$ with identical STJ diameter. Valvesparing procedures that prevent AA expansion are preferable. (J Thorac Cardiovasc Surg 2013;146:1227-31)

Aortic valve performance is highly dependent on the geometry of the aortic root. This dependency can be demonstrated in valve-sparing aortic replacement procedures inasmuch as the valve can be repaired by replacing only the aneurysmatic root while retaining the native cusps, a procedure usually performed without cusp intervention. In a previous study, we ${ }^{1}$ showed how coaptation and mechanical stresses are affected by the aortic annulus (AA) diameter. Furthermore, it has also been suggested that sinotubular junction (STJ) diameter can affect valve function. ${ }^{2}$

In aortic valve-sparing procedures, the surgeon is able to control various geometric parameters of the graft. The geometry depends on the type of procedure, David ${ }^{3}$ or Yacoub,${ }^{4}$ the diameter of the graft, and the AA diameter

\footnotetext{
From the School of Mechanical Engineering, ${ }^{a}$ Faculty of Engineering, Tel Aviv University, Tel Aviv, Israel; the Department of Thoracic and Cardiovascular Surgery, ${ }^{\text {b }}$ Saarland University Medical Center, Homburg, Germany; and the Department of Cardiothoracic Surgery, ${ }^{\mathrm{c}}$ Chaim Sheba Medical Center, Tel Hashomer, Israel.

This work was partially supported by a grant from the Nicholas and Elizabeth Slezak Super Center for Cardiac Research and Biomedical Engineering at Tel Aviv University.

Disclosures: Authors have nothing to disclose with regard to commercial support.

Received for publication Oct 1, 2012; revisions received Dec 10, 2012; accepted for publication Jan 14, 2013; available ahead of print Feb 11, 2013.

Address for reprints: Ehud Raanani, MD, Cardiac Surgery, Sheba Medical Center, Tel

Hashomer, 52621, Israel (E-mail: ehud.raanani@sheba.health.gov.il).

$0022-5223 / \$ 36.00$

Copyright (c) 2013 by The American Association for Thoracic Surgery

http://dx.doi.org/10.1016/j.jtcvs.2013.01.030
}

$\left(d_{\mathrm{AA}}\right)$, if the procedure includes annuloplasty. Lansac and associates ${ }^{5}$ suggested the addition of ring annuloplasty to root remodeling, and for this procedure they ${ }^{6}$ proposed using a $d_{\mathrm{AA}}$ smaller than the STJ diameter $\left(d_{\mathrm{STJ}}\right)$ without systematic confirmation of the relationship. Few clinical studies have found that the geometry of the graft is an important factor for valve performance and durability. ${ }^{7}$

Numerical models can provide valve mechanic information regarding various geometries of the valve and root that would be unpredictable during surgery. The influence of root geometry on valve mechanics has been studied in several previous numerical models, using finite element analysis $^{8-11}$ and fluid-structure interaction (FSI) models. ${ }^{1,12,13}$ Most of these studies compared only cases with and without aortic sinuses ${ }^{8,12,13}$ or investigated different valve-sparing procedures, ${ }^{9-11}$ whereas our previous study ${ }^{1}$ introduced an FSI model and constructed the only parametric study of root geometry. Although this parametric study examined 6 geometries with different $d_{\mathrm{AA}} \mathrm{s}$, it focused only on the diastolic phase, excluding the systolic flow shear stress that had been previously suggested as a possible initiator of calcification. ${ }^{14}$ A systematic parametric study that examines various aortic root geometries with different combinations of $d_{\mathrm{AA}} \mathrm{s}$ and $d_{\mathrm{STJ}} \mathrm{s}$ has not yet been carried out. Such a study, with various $d_{\mathrm{AA}} \mathrm{s}$ and $d_{\mathrm{STJ}} \mathrm{s}$, is needed to improve valve-sparing procedures.

More specifically, it would be advantageous to identify the graft size and the ratio between the $d_{\mathrm{AA}} \mathrm{S}$ and $d_{\mathrm{STJ}} \mathrm{S}$ 


\section{Abbreviations and Acronyms \\ $\mathrm{AA}=$ aortic annulus \\ $d_{\mathrm{AA}}=$ aortic annulus diameter \\ $d_{\mathrm{STJ}}=$ sinotubular junction diameter \\ FSI $=$ fluid-structure interaction \\ $\bar{h}_{C}=$ average coaptation height \\ $\mathrm{STJ}=$ sinotubular junction}

that would yield in normal valve dynamics and minimum stress distribution in the cusps. Although it is known that both the $d_{\mathrm{AA}} \mathrm{S}$ and $d_{\mathrm{STJ}} \mathrm{S}$ directly affect valve dynamics after valve-sparing procedures, ${ }^{1,2,15}$ no studies on the ratio between these diameters have been reported. The objective of the present study was to determine the influence of changes in $d_{\mathrm{AA}}$ and STJ-to-AA ratio on the hemodynamics and tissue mechanics of the valve.

\section{METHODS}

A 3-dimensional geometry of a tricuspid aortic valve and root was reconstructed using normal dimensions and geometric relationships, including the 3 cusps and aortic sinuses. ${ }^{16}$ This base geometry has a $d_{\mathrm{AA}}$ of $24 \mathrm{~mm}$ and STJ-to-AA diameter ratio $\left(d_{\mathrm{STJ}} / d_{\mathrm{AA}}\right)$ of 1.1 , and therefore its cusps and root dimensions are within the literature range of healthy, normal valves. ${ }^{16,17}$ Four geometries, with a $d_{\mathrm{AA}}$ between 22 and $28 \mathrm{~mm}$, were calculated from the base geometry with an applied outer pressure that expanded or shrank the initial AA. Sixteen geometries, with a $d_{\mathrm{STJ}} / d_{\mathrm{AA}}$ between 0.8 and 1.4, were then calculated in the same manner, 4 geometries for each $d_{\mathrm{AA}}$. By this method the cusp sizes fit the geometry of the root similar to actual valves, as for example expanded roots that have stretched cusps. Figure 1 illustrates the 16 calculated geometries that were used as the initial configurations of the valve and root in the "dry" finite element models, assuming zero stress in the tissues. Five additional FSI models were also constructed. The initial geometries of the FSI models have a $d_{\mathrm{STJ}} / d_{\mathrm{AA}}$ between 0.6 and 1.4 with a $d_{\mathrm{AA}}=24 \mathrm{~mm}$. Two straight rigid tubes were added upstream and downstream, respectively, to move the flow boundary conditions away from the compliant root. The AA and STJ were assumed to be pinned to the rigid tubes and therefore did not have transitional degrees of freedom.

The structural solver used an implicit nonlinear dynamic analysis using the finite element method. A Collagen Fiber Network material model ${ }^{18}$ was used for the cusps' tissues. The hyperelastic behavior of the elastin, collagen, and tissues of the sinuses (Figure 2, A) is based on published experimental stress-strain curves from porcine aortic valves ${ }^{19}$ and roots ${ }^{20}$ in the dry models with appropriate thickness. ${ }^{18,20}$ For the FSI model, where there is a blood pressure load on the walls of the root, the sinuses were assumed to be part of a graft with polyethylene terephthalate material properties. ${ }^{9}$ A master-slave contact algorithm was used between the cusps. ${ }^{21}$ Shell elements were used to model the cusps and the root. Virtual surfaces that represent the thickness of the cusps were added in the FSI models. The flow was assumed laminar and the blood Newtonian and isothermal. Although the Newtonian fluid assumption is not valid everywhere in the circulation system, it is valid in the aorta. ${ }^{22}$ A finite volume method was used for solving the unsteady 3-dimensional Navier-Stokes and mass conservation equations using the Eulerian approach. ${ }^{21}$ Figure 2, $B$, demonstrates the physiologic time-dependent pressures that were used at the aortic and ventricular boundaries in the FSI models. A suitable transvalvular pressure was applied on the cusps in the "dry" models. The FSI models were solved by a partitioned solver with nonconformal meshes. ${ }^{21}$ The structural problem was solved by Abaqus 6.11 (Simulia, Providence,
RI) finite element software. For the FSI models, FlowVision HPC 3.08 (Capvidia, Leuven, Belgium) was the flow solver and managed the coupling between the 2 codes.

\section{RESULTS}

The results in this section are presented for the diastolic and systolic phases. The diastolic results are from the 16 "dry" models and include the average coaptation height and mechanical stress distribution in the tissues. These results are compared at $400 \mathrm{~ms}$ after the beginning of the opening, which is about $120 \mathrm{~ms}$ after diastole. This timing was chosen because the valve was under a relatively large pressure load with somewhat stable kinematics. The influence of the systolic hemodynamics on the tissues is based on the 5 FSI models. Obviously, the flow shear stresses on the cusps during peak systole are calculated from the FSI models.

The coaptation is calculated from the closed position of the 16 valves. Two-dimensional deformed diastolic configurations are presented in Figure 3. The projection plane was selected to best illustrate valve coaptation in a similar fashion to echocardiography measurements. ${ }^{1}$ The average coaptation height $\left(\bar{h}_{C}\right)$ is also marked for each case in Figure 3, and is defined as the coaptation area divided by the freeedge length. The cases with $d_{\mathrm{AA}}=24 \mathrm{~mm}$ have the largest coaptation relative to the other cases with equal $d_{\mathrm{STJ}} / d_{\mathrm{AA}}$, except for the case with $d_{\mathrm{STJ}} / d_{\mathrm{AA}}=1.2$. Also, the $\bar{h}_{C}$ increases with the decrease of $d_{\mathrm{STJ}} / d_{\mathrm{AA}}$ for $d_{\mathrm{AA}}$ between 24 and $28 \mathrm{~mm}$, but not for $d_{\mathrm{AA}}=22 \mathrm{~mm}$. A possible explanation is that the cusp prolapse is more severe in the cases with $d_{\mathrm{AA}}=22 \mathrm{~mm}$.

Figure 4 presents the maximum principal stress contours on the deformed configurations of the closed valves. We denoted the maximum principal stress simply as stress to characterize its spatial distribution. It can be clearly seen that the cases with $d_{\mathrm{AA}}$ between 26 and $28 \mathrm{~mm}$ and $d_{\mathrm{STJ}} / d_{\mathrm{AA}}$ between 1.2 and 1.4 are not fully closed. This fact could explain the low $\bar{h}_{C}$ in these cases, even though the coaptation is seen at the symmetric section of Figure 3 (marked as a dashed line on the bottom right of Figure 4). In all the cases, the maximum stress magnitudes are found in the fiber bundles. This difference between the collagen and elastin is even larger in the not fully closed cases. For example, the case with $d_{\mathrm{AA}}=28 \mathrm{~mm}$ and $d_{\mathrm{STJ}} / d_{\mathrm{AA}}=1.4$ has the largest stress magnitude of 1.27 MPa in the fibers, but it has a low magnitude of only $0.65 \mathrm{MPa}$ in the elastin, which is lower relative to the other cases with the same $d_{\mathrm{STJ}} / d_{\mathrm{AA}}$. For the cases with $d_{\mathrm{AA}}$ between 24 and $26 \mathrm{~mm}$, the highest stress values are found in the cases with $d_{\mathrm{STJ}} / d_{\mathrm{AA}}=0.8$. The 5 cases with $\bar{h}_{C}$ greater than $3 \mathrm{~mm}, d_{\mathrm{AA}}=22 \mathrm{~mm}$, and $d_{\mathrm{STJ}} / d_{\mathrm{AA}}=1.2$ or $d_{\mathrm{AA}}$ between 24 and $26 \mathrm{~mm}$ and $d_{\mathrm{STJ}} / d_{\mathrm{AA}}$ between 0.8 and 1.0, have similar stress distribution and maximum stress magnitudes.

The peak systole was compared from the 5 FSI models with $d_{\mathrm{AA}}=24 \mathrm{~mm}$. Here the peak systole is defined as the time when the valve reached its maximum opening state. 


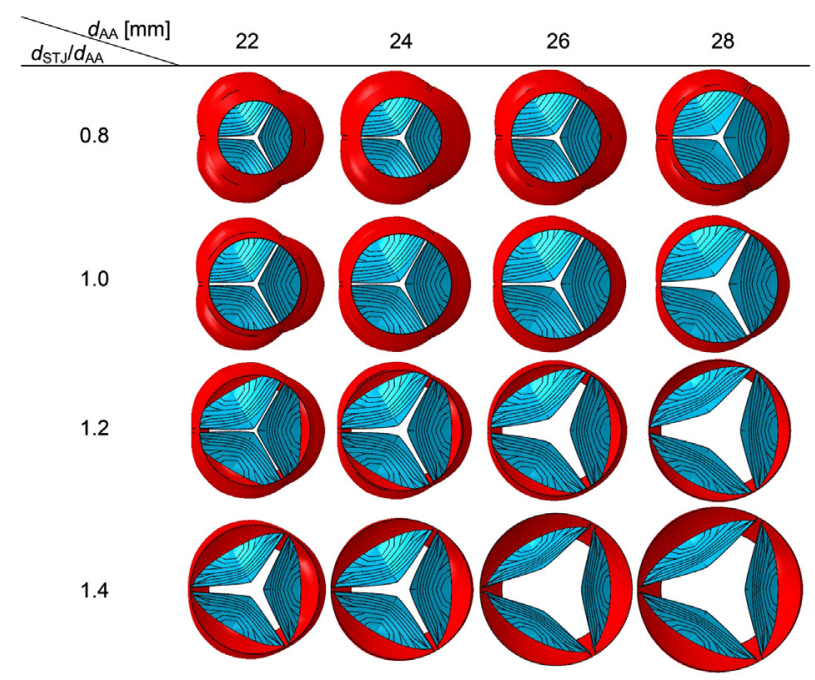

FIGURE 1. Views from the aorta on the 16 initial geometries of the "dry" models with different $d_{\mathrm{AA}}$ and $d_{\mathrm{STJ}} . d_{A A}$, Aortic annulus diameter; $d_{S T J}$, sinotubular junction diameter.

In all 5 FSI models, peak systole was at $96 \mathrm{~ms}$ after the beginning of the opening, similar to other studies that used the same definition, but in "dry" models. ${ }^{23}$ Obviously, the opening area increased with the increase of the $d_{\mathrm{STJ}} / d_{\mathrm{AA}}$,
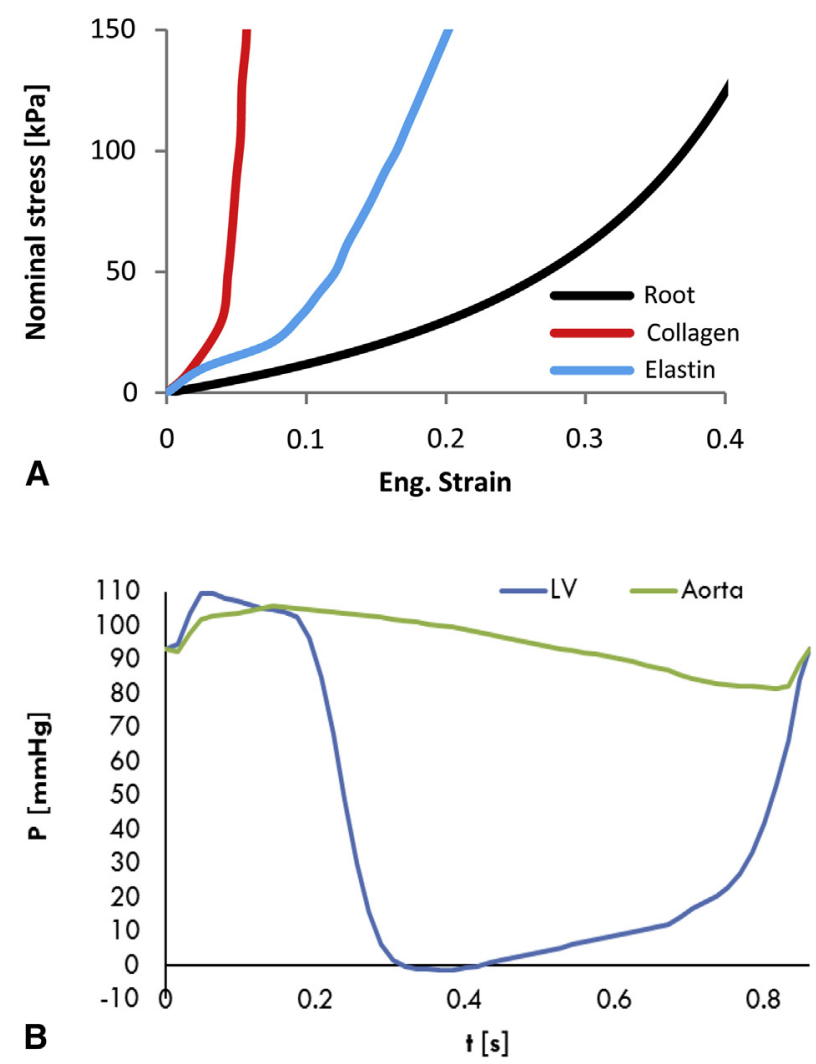

FIGURE 2. A, Stress-strain curves for the hyperelastic materials in the root and for the collagen and elastin of the cusps. B, The aortic and left ventricular pressure as a function of time. $L V$, Left ventricle.

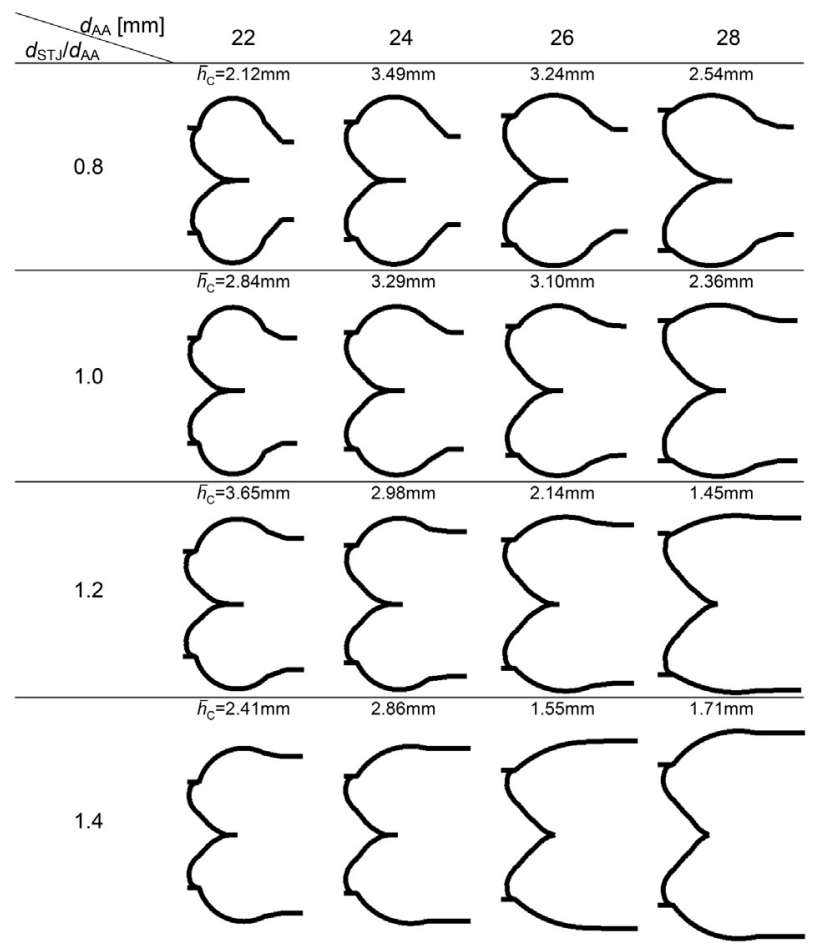

FIGURE 3. Projected deformed configurations of the closed valves with different $d_{\mathrm{AA}}$ and $d_{\mathrm{STJ}} / d_{\mathrm{AA}}$. The cases with $d_{\mathrm{AA}}$ between 26 and $28 \mathrm{~mm}$ and $d_{\mathrm{STJ}} / d_{\mathrm{AA}}$ between 1.2 and 1.4 are not closed, even though this view does not demonstrate this fact. The average coaptation height $\left(\bar{h}_{C}\right)$ is marked above each case. $d_{A A}$, Aortic annulus diameter; $\mathrm{d}_{S T J}$, sinotubular junction diameter.

from 0.5 up to $1.4 \mathrm{~cm}^{2}$ for the cases with a $d_{\mathrm{STJ}} / d_{\mathrm{AA}}$ of 0.6 and 1.4, respectively. However, the opening area relative to the STJ area was actually decreased with an increase of the $d_{\mathrm{STJ}} / d_{\mathrm{AA}}$. This might be explained by the stretched cusps in the cases with a $d_{\mathrm{STJ}}$ greater than the $d_{\mathrm{AA}}$, so that the motion of the valve was restrained. Increasing $d_{\mathrm{STJ}} / d_{\mathrm{AA}}$ also reduces resistance to the flow and therefore increases the flow rate under the same pressure drop. Figure 5 presents flow shear stress contours on the ventricular side of the cusp for the 5 FSI models. Reducing the $d_{\mathrm{STJ}} / d_{\mathrm{AA}}$ increases the shear stress values and its spatial distribution on the cusps. In all the cases, the highest shear stress magnitudes were found in the coapting region near the connection of the commissures and the free edge. The shear stress values in the belly region are significantly lower than those found in the coapting region.

\section{DISCUSSION}

Aortic valve-sparing procedures have a vast influence on valve performance, despite the fact that only the geometry of the root is adjustable in these techniques. The present study investigated the influence of the root geometry on several parameters that can describe valve performance. The initial geometries are based on dimensions within the literature range for nondiseased valves, ${ }^{17,24}$ but with 


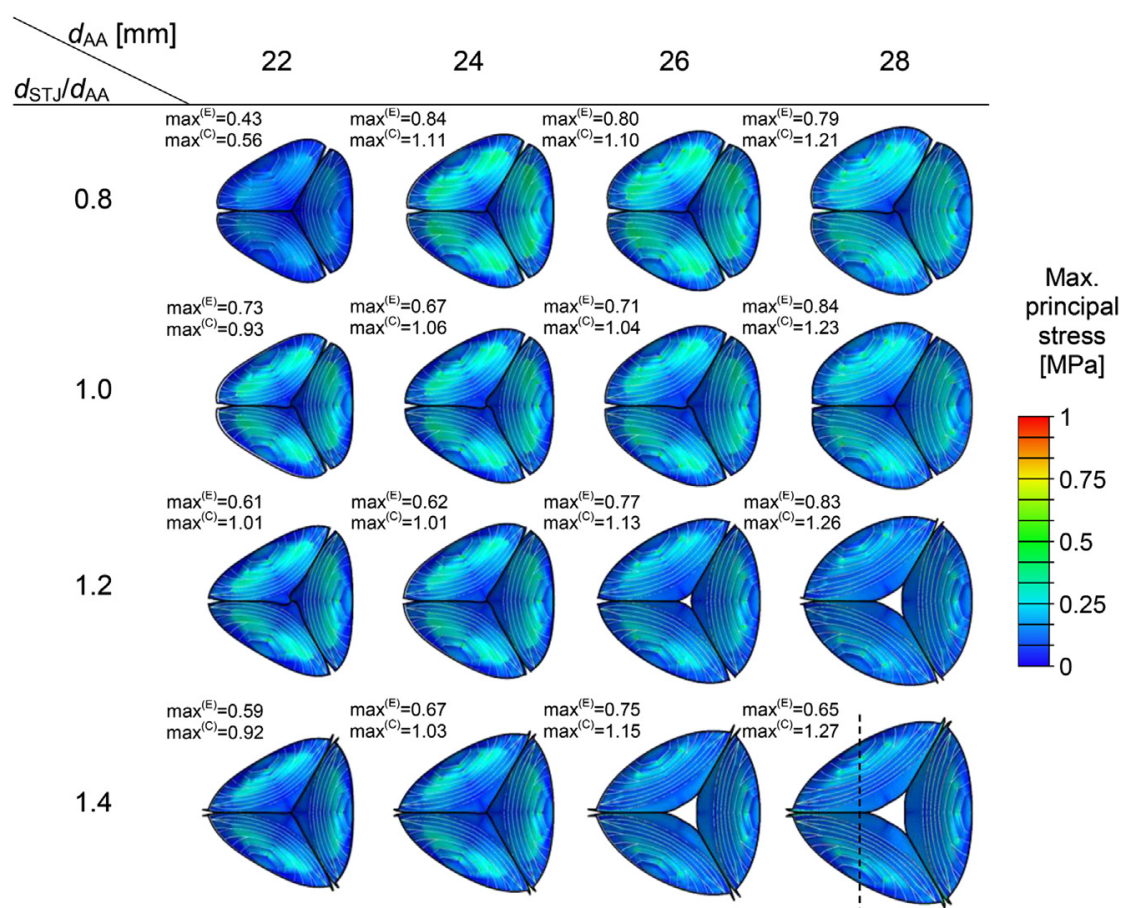

FIGURE 4. A plot of maximum principal stress contours on the deformed configurations of the closed valves with different $d_{\mathrm{AA}}$ and $d_{\mathrm{STJ}} / d_{\mathrm{AA}}$. The maximum values $(\mathrm{MPa})$ in the collagen fibers and the elastin are marked with $\max ^{(\mathrm{C})}$ and $\max ^{(\mathrm{E})}$, respectively. $d_{A A}$, Aortic annulus diameter; $d_{S T J}$, sinotubular junction diameter.

smaller cusp size than recently measured intraoperatively. ${ }^{25}$ However, these dimensions are appropriate for comparing the results of the above parametric studies inasmuch as all the models have identical initial geometric heights. The coaptation and mechanical stress in the cusps' tissues were compared during diastole. The coaptation indicates the quality of closure since it provides a safety margin for preventing regurgitation, whereas the maximum principal stress could imply valve durability. ${ }^{17}$ The parameters chosen to describe peak systole were the opening area, which directly affects the blood flow, and the flow shear stress on the cusps that is related to calcification initiation. ${ }^{14}$ Obviously, the blood flow needed to be modeled to calculate the last parameter, and therefore systole was evaluated from FSI models.

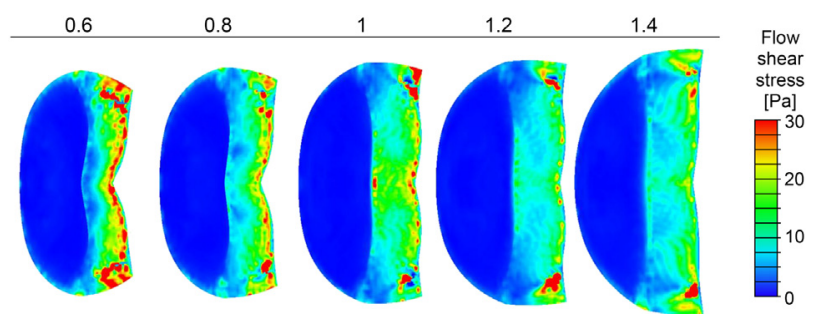

FIGURE 5. A plot of flow shear stress contours on the deformed configurations of a single cusp during peak systole for $d_{\mathrm{AA}}=24 \mathrm{~mm}$ and $d_{\mathrm{STJ}} / d_{\mathrm{AA}}$ between 0.6 and 1.4. $d_{A A}$, Aortic annulus diameter; $d_{S T J}$, sinotubular junction diameter.
Inasmuch as there is no blood flow through the valve at diastole, we used simplified "dry" models for the comprehensive parametric study with 16 cases. It was found that for most of the $d_{\mathrm{STJ}}$ to $d_{\mathrm{AA}}$ ratios, the cases with $d_{\mathrm{AA}}=24 \mathrm{~mm}$ had the largest $\bar{h}_{C}$. Also, there is a negative correlation between $\bar{h}_{C}$ and $d_{\mathrm{STJ}} / d_{\mathrm{AA}}$ for $24 \leq d_{\mathrm{AA}} \leq 28 \mathrm{~mm}$, and there are 5 cases with $\bar{h}_{C}$ greater than $3 \mathrm{~mm}$, specifically $d_{\mathrm{AA}}=$ $22 \mathrm{~mm}$ and $d_{\mathrm{STJ}} / d_{\mathrm{AA}}=1.2$ or $24 \leq d_{\mathrm{AA}} \leq 26 \mathrm{~mm}$ and $0.8 \leq d_{\mathrm{STJ}} / d_{\mathrm{AA}} \leq 1.0$. It should be emphasized that $\bar{h}_{C}$ is an averaged coaptation height, which is calculated as the coaptation area divided by the free-edge length, and therefore its values are smaller than usually measured in echocardiography. This parameter, which indicates closure quality throughout the cusps, demonstrates one of the advantages of 3-dimensional numerical models; although not measured clinically, we have previously shown that it correlates well with earlier findings in 3-dimensional models. ${ }^{1}$ For example, the cases with $\bar{h}_{C}$ less than $2 \mathrm{~mm}$ could not be closed and most probably regurgitated during diastole.

The maximum principal stress distributions in the 16 dry models were also compared during diastole. Lower stress magnitude is required inasmuch as excessive stress values can damage the cusps and reduce valve durability. ${ }^{17}$ Intuitively, the maximum stress values were found in the collagen and not in the tissues, because the collagen is considerably stiffer. Nevertheless, durability should be assessed from stress distribution in the elastin because it is more sensitive and would probably be injured first. The 5 
most clinically interesting cases, with $\bar{h}_{C}$ greater than $3 \mathrm{~mm}$, had similar stress distribution in the elastin (Figure 4), whereas the maximum values were $20 \%$ lower in the cases with larger $d_{\mathrm{STJ}} / d_{\mathrm{AAA}}$. Therefore, the cases with $24 \leq d_{\mathrm{AA}} \leq 26 \mathrm{~mm}$ and $d_{\mathrm{STJ}} / d_{\mathrm{AA}}=1.0$ are preferable to those with the same diameter of $d_{\mathrm{STJ}} / d_{\mathrm{AA}}=0.8$.

From the above results, as well as from our previous study, ${ }^{1}$ it seems reasonable to use the more advanced FSI models on the 5 cases with $d_{\mathrm{AA}}=24 \mathrm{~mm}$. These cases were compared at peak systole, or $96 \mathrm{~ms}$ after the beginning of the opening, which is in accord with previous findings. ${ }^{23}$ The opening area relative to the STJ area decreases with the increase of $d_{\mathrm{STJ}} / d_{\mathrm{AA}}$, from $33 \%$ to $16 \%$ for $d_{\mathrm{STJ}}$ to $d_{\mathrm{AA}}$ ratios of 0.6 and 1.4, respectively. Therefore, the large opening area of the cases with a $d_{\mathrm{STJ}} / d_{\mathrm{AA}}$ of 1.2 or more is caused by the initial configuration and by blood flow from the ventricle. The flow shear stress values decrease with the increase of $d_{\mathrm{STJ}} / d_{\mathrm{AA}}$. Since lower flow shear stresses on the tissues are desirable, ${ }^{14}$ this finding indicates that the STJ size should probably not be less than the size of the AA. In a valve-sparing procedure, where the $d_{\mathrm{STJ}}$ is fixed by the size of the graft, annular stabilization is also required to prevent AA expansion after surgery. This stabilization can be achieved either by a reimplantation (David) procedure or a Yacoub procedure with annuloplasty, where various techniques could be used, ${ }^{5,26,27}$ thereby demonstrating a further indication that a $d_{\mathrm{STJ}} / d_{\mathrm{AA}}$ greater than 1.0 is not necessarily warranted, even though similar stress distribution exists for $d_{\mathrm{STJ}} / d_{\mathrm{AA}}$ of 0.8 and 1.0 .

\section{CONCLUSIONS}

On the basis of our results, those cases with $24 \leq d_{\mathrm{AA}} \leq 26$ $\mathrm{mm}$ and $d_{\mathrm{STJ}} / d_{\mathrm{AA}}=1.0$ have larger coaptation relative to the other cases, lower stress in the tissues during diastole, and lower flow shear stress during systole. Valve-sparing procedures that prevent AA expansion may prove to be more durable inasmuch as lower flow shear stresses act on the surface of the cusps.

\section{References}

1. Marom G, Haj-Ali R, Rosenfeld M, Schäfers HJ, Raanani E. Aortic root numeric model: annulus diameter prediction of effective height and coaptation in postaortic valve repair. J Thorac Cardiovasc Surg. 2013;145:406-11.e1.

2. Maselli D, De Paulis R, Scaffa R, Weltert L, Bellisario A, Salica A, et al. Sinotubular junction size affects aortic root geometry and aortic valve function in the aortic valve reimplantation procedure: an in vitro study using the Valsalva graft. Ann Thorac Surg. 2007;84:1214-8.

3. David TE, Feindel CM. An aortic valve-sparing operation for patients with aortic incompetence and aneurysm of the ascending aorta. J Thorac Cardiovasc Surg. 1992;103:617-22.
4. Sarsam MAI, Yacoub M. Remodeling of the aortic valve anulus. $J$ Thorac Cardiovasc Surg. 1993;105:435-8.

5. Lansac E, Di Centa I, Varnous S, Rama A, Jault F, Duran CMG, et al. External aortic annuloplasty ring for valve-sparing procedures. Ann Thorac Surg. 2005; 79:356-8.

6. Lansac E, Di Centa I, Raoux F, Raffoul R, Al Attar N, Rama A, et al. Aortic annuloplasty: towards a standardized approach of conservative aortic valve surgery. Multimedia Manual of Cardio-Thoracic Surgery. 2007;2007(0329) http://dx.doi.org/10.1510/mmcts.2006.001958.

7. De Paulis R, De Matteis GM, Nardi P, Scaffa R, Buratta MM, Chiariello L. Opening and closing characteristics of the aortic valve after valve-sparing procedures using a new aortic root conduit. Ann Thorac Surg. 2001;72:487-94.

8. Beck A, Thubrikar MJ, Robicsek F. Stress analysis of the aortic valve with and without the sinuses of Valsalva. J Heart Valve Dis. 2001;10:1-11.

9. Grande-Allen KJ, Cochran RP, Reinhall PG, Kunzelman KS. Re-creation of sinuses is important for sparing the aortic valve: a finite element study. $J$ Thorac Cardiovasc Surg. 2000;119:753-63.

10. Soncini M, Votta E, Zinicchino S, Burrone V, Mangini A, Lemma M, et al. Aortic root performance after valve sparing procedure: a comparative finite element analysis. Med Eng Phys. 2009;31:234-43.

11. Soncini M, Votta E, Zinicchino S, Burrone V, Fumero R, Mangini A, et al. Finite element simulations of the physiological aortic root and valve sparing corrections. J Mech Med Biol. 2006;6:91-9.

12. Ranga A, Bouchot O, Mongrain R, Ugolini P, Cartier R. Computational simulations of the aortic valve validated by imaging data: evaluation of valve-sparing techniques. Interact Cardiovasc Thorac Surg. 2006;5:373-8.

13. Katayama S, Umetani N, Sugiura S, Hisada T. The sinus of Valsalva relieves abnormal stress on aortic valve leaflets by facilitating smooth closure. $J$ Thorac Cardiovasc Surg. 2008;136:1528-35.

14. Saikrishnan N, Yap CH, Milligan NC, Vasilyev NV, Yoganathan AP. In vitro characterization of bicuspid aortic valve hemodynamics using particle image velocimetry. Ann Biomed Eng. 2012;40:1760-75.

15. El Khoury G, Vanoverschelde JL, Glineur D, Poncelet A, Verhelst R, Astarci P, et al. Repair of aortic valve prolapse: experience with 44 patients. Eur J Cardiothorac Surg. 2004;26:628-33.

16. Haj-Ali R, Marom G, Ben Zekry S, Rosenfeld M, Raanani E. A general threedimensional parametric geometry of the native aortic valve and root for biomechanical modeling. J Biomech. 2012;45:2392-7.

17. Thubrikar M. The aortic valve. Boca Raton (FL): CRC Press; 1990.

18. Kim HS. Nonlinear multi-scale anisotropic material and structural models for prosthetic and native aortic heart valves [PhD thesis]. Atlanta (GA): Georgia Institute of Technology; 2009.

19. Missirlis YF, Chong M. Aortic valve mechanics-part 1: material properties of natural porcine aortic valves. J Bioeng. 1978;2:287-300.

20. Gundiah N, Kam K, Matthews PB, Guccione J, Dwyer HA, Saloner D, et al Asymmetric mechanical properties of porcine aortic sinuses. Ann Thorac Surg. 2008;85:1631-8.

21. Marom G, Haj-Ali R, Raanani E, Schäfers HJ, Rosenfeld M. A fluid-structure interaction model of coaptation in fully compliant aortic valves. Med Biol Eng Comput. 2012;50:173-82.

22. Li JKJ. Dynamics of the vascular system. Singapore: World Scientific; 2004.

23. Jermihov P, Jia L, Sacks MS, Gorman R, Gorman J, Chandran K. Effect of geometry on the leaflet stresses in simulated models of congenital bicuspid aortic valves. Cardiovasc Eng Technol. 2011;2:48-56.

24. Swanson WM, Clark RE. Dimensions and geometric relationships of the human aortic value as a function of pressure. Circ Res. 1974;35:871-82.

25. Schäfers HJ, Schmied W, Marom G, Aicher D. Cusp height in aortic valves. J Thorac Cardiovasc Surg. 2012 Jul 30. [Epub ahead of print].

26. Fattouch K, Sampognaro R, Speziale G, Ruvolo G. New technique for aortic valve functional annulus reshaping using a handmade prosthetic ring. Ann Thorac Surg. 2011;91:1154-8.

27. Schomburg JL, Lahti MT, Ruth GR, Bianco RW. Internal aortic annuloplasty: a novel technique. J Investig Surg. 2011;24:222-6. 